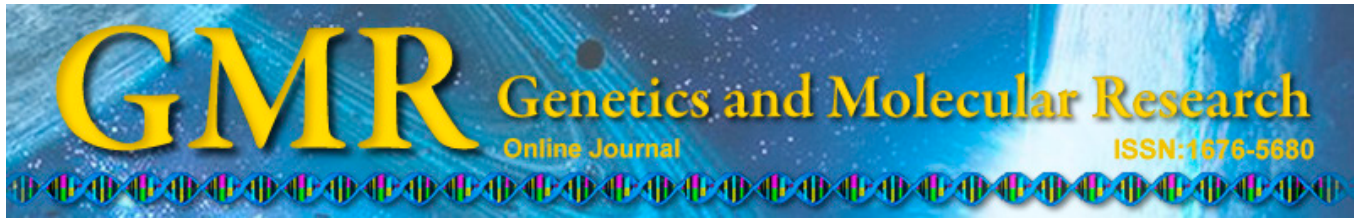

\title{
Molecular characterization of aflatoxigenic and non-aflatoxigenic Aspergillus flavus isolates collected from corn grains
}

\author{
M.A. Mahmoud ${ }^{1}$, H.M. Ali ${ }^{2}$, A.R.M. El-Aziz ${ }^{2}$, \\ M.R. Al-Othman ${ }^{2}$ and A.S. Al-Wadai ${ }^{2}$ \\ ${ }^{1}$ Plant Pathology Research Institute, Agricultural Research Center, \\ Giza, Egypt \\ ${ }^{2}$ Botany and Microbiology Department, College of Science, \\ King Saud University, Riyadh, Kingdom of Saudi Arabia \\ Corresponding author: A.R.M. El-Aziz \\ E-mail: aabdelaziz@ksu.edu.sa
}

Genet. Mol. Res. 13 (4): 9352-9370 (2014)

Received September 24, 2013

Accepted May 8, 2014

Published November 11, 2014

DOI http://dx.doi.org/10.4238/2014.November.11.2

\begin{abstract}
Twelve species from six fungal genera were found to be associated with corn (Zea mays L.) grain samples collected from three main regions of Saudi Arabia. The average frequencies of the most common genera were Aspergillus (11.4\%), Fusarium (9.5\%), Penicillium (5.1\%), and Alternaria (5.8\%). Fifteen isolates of Aspergillus flavus were screened by HPLC for their ability to produce aflatoxins (AF). The percentage of aflatoxigenic A. flavus isolates was $53 \%$. Eight isolates produced AF, at concentrations ranging 0.7-2.9 ppb. Random amplified polymorphic DNA (RAPD) and inter-simple sequence repeat (ISSR) molecular markers were used to genetically characterize isolates of A. flavus and to discriminate between the aflatoxigenic and non-aflatoxigenic isolates. RAPD and ISSR analysis revealed a high level of genetic diversity in the A. flavus population, which was useful for genetic characterization. The clustering in the RAPD and ISSR dendrograms obtained was unrelated to geographic
\end{abstract}


origin. The RAPD and ISSR markers could not discriminate between aflatoxigenic and non-aflatoxigenic isolates, but the ISSR primers were somewhat better.

Key words: Aspergillus flavus; Random amplified polymorphic DNA; Corn; Inter-simple sequence repeats

\section{INTRODUCTION}

Corn (Zea mays L.) is one of the main cereals that is used as a source of food, forage, and processed products for industry. World corn production is approximately 790 million tons, and as a staple food, it provides more than one-third of the calories and protein in some countries (Chulze, 2010). Mycotoxins contaminate approximately $25-50 \%$ of the total crops harvested, and because molds thrive in tropical environments, they damage approximately $80 \%$ of the crops in tropical regions. Mycotoxins, such as aflatoxins (AF), ochratoxins, zeralenone, trichothecenes, and fumonisins, are the major mycotoxins that influence public health and agricultural crops.

In Saudi Arabia, there is a lack of accurate data on Aspergillus flavus contamination of corn. Few studies concerning A. flavus and AF production have been conducted (Abd ElAziz Abeer et al., 2012; Yassin et al., 2012; Mahmoud et al., 2013) and no major survey has addressed this topic. AF are produced by a large number of Aspergillus species. The main producers of $\mathrm{AF}$ are A. flavus, A. parasiticus, A. nomius, A. pseudotamarii, A. parvisclerotigenus and A. bombycis (Frisvad et al., 2005). AF occur in several different chemical forms, designated AF B1, B2, G1, and G2 (Murphy et al., 2006). AF production depends on various factors such as the presence of toxigenic fungi, the chemical composition of the substrate, moisture content, relative humidity, temperature, and the time course of fungal growth. However, high incidences of AF contamination in cereal seeds and animal feed have been reported worldwide (Placinta et al., 1999). When AF are present in foods at sufficiently high levels, these fungal metabolites can have toxic effects that range from acute (liver or kidney deterioration) to chronic (e.g., liver cancer) toxicity and can be mutagenic and teratogenic. A promising method for controlling these toxigenic fungi is to use competitive biological control through colonizing soils with nontoxigenic A. flavus isolates, which can suppress their toxigenic counterparts (Yin et al., 2008). In experiments involving plants artificially infected with nontoxigenic fungal strains, a reduction in AF contamination of up to $90 \%$ was observed (Tran-Dinh et al., 1999). However, before biological control strategies can be implemented, the genetic diversity within this fungal group and the critical factors leading to the retention or loss of characteristics such as toxigenic capacity and virulence to agricultural crops must be investigated.

The genetic techniques for performing such analyses include the examination of random amplified polymorphic DNA (RAPD) markers and inter-simple sequence repeats (ISSR). The RAPD technique has been used to detect genetic variability between isolates of $A$. flavus and related species (Batista et al., 2008; Gehlot et al., 2011; Irshad and Nawab, 2012) and to discriminate between aflatoxigenic and non-aflatoxigenic isolates of A. flavus (Lourenço et al., 2007; Gashgari et al., 2010; Sepahvand et al., 2011). The ISSR technique has been employed to investigate the diversity and population structure of A. flavus (Tran-Dinh and Carter, 2000; 
Batista et al., 2008; Tran-Dinh et al., 2009; Hadrich et al., 2010; Wang et al., 2012) and to determine the similarities and dissimilarities between aflatoxigenic and non-aflatoxigenic isolates of this species (Tran-Dinh et al., 2009; Hatti et al., 2010).

The aims of the present study were therefore 1) to survey the presence of A. flavus in corn in three main regions in Saudi Arabia; 2) to test methods for the detection and determination of AF involving HPLC; and 3) to characterize and discriminate aflatoxigenic and nonaflatoxigenic isolates genetically using RAPD and ISSR markers.

\section{MATERIAL AND METHODS}

\section{Collection of samples}

Fifteen samples (250 g each) of corn grain were collected from different markets located in Riyadh, Dammam, and Abha regions (Figure 1) in the Kingdom of Saudi Arabia during March 2011. The samples were stored at $2{ }^{\circ} \mathrm{C}$ until use (Czerwiecki et al., 2002).

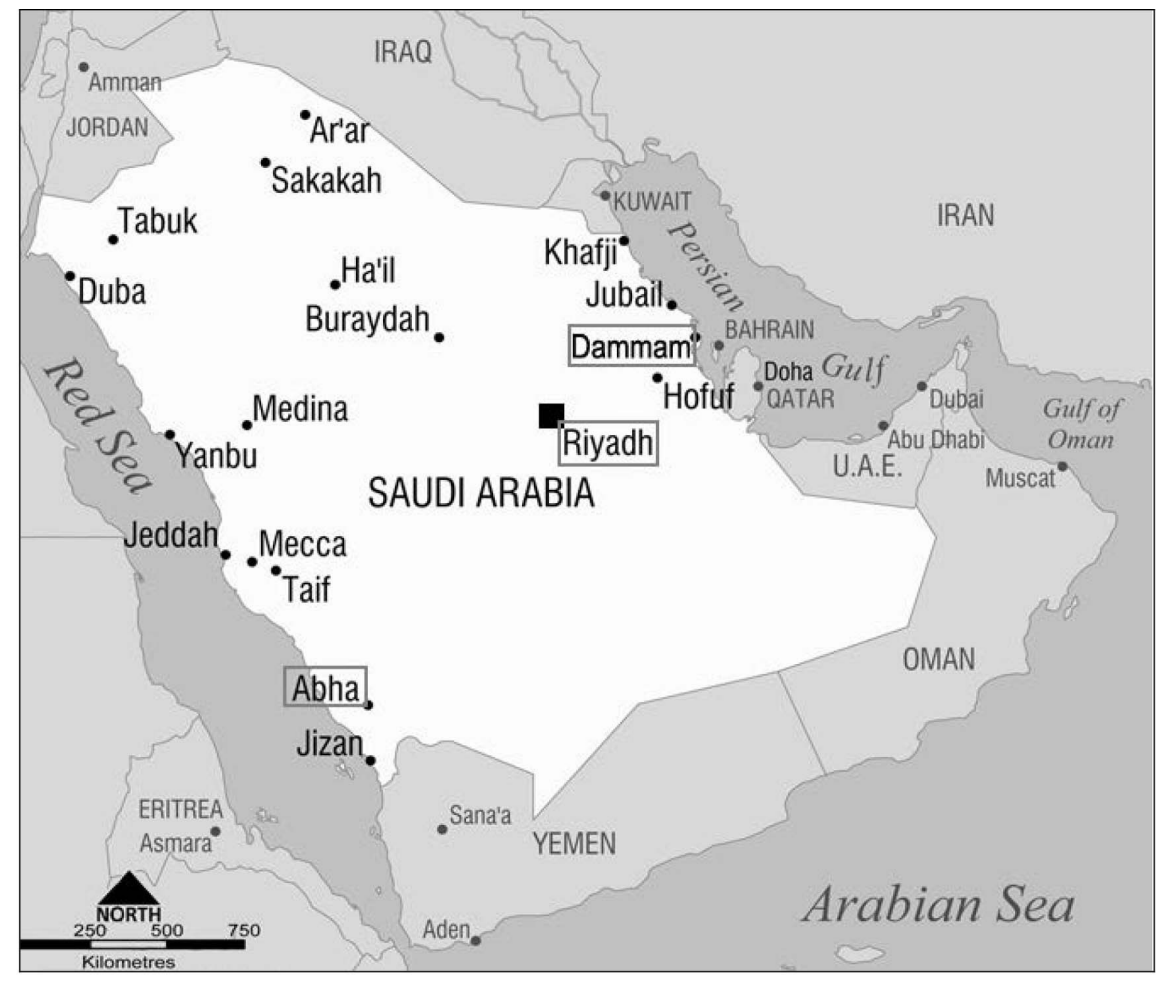

Figure 1. Map of Saudi Arabia indicating the regions which corn grain samples were collected during March 2012.

\section{Isolation, purification, and identification of pathogens}

Samples were surface-sterilized with $5 \%$ sodium hypochlorite for $1 \mathrm{~min}$, before they were rinsed three times with sterile distilled water. Five grains were placed randomly 
on potato dextrose agar (PDA) on three 9-cm Petri dishes. The Petri dishes were incubated at $25^{\circ} \mathrm{C}$ and observed daily for emergence of colonies for 5 days, after which the colonies were counted. Isolates were purified by single spore method and then transferred to PDA slants. All the isolates of fungal species were identified up to the species level using keys and manuals (Raper and Fennell, 1965; Domsch et al., 1993). The isolation frequencies of fungal species were calculated according to the method of González et al. (1995). Identification of fungal isolates was carried out on the basis of morphological and microscopic characteristics at the Regional Center for Mycology and Biotechnology, Al-Azhar University, Cairo, Egypt.

\section{Aflatoxin production in different culture media}

For the determination of AF production based on fluorescence in culture media, all of the A. flavus isolates obtained were cultivated on PDA at $25^{\circ} \mathrm{C}$ for 7 days. A mycelium plug from each strain was placed on the center of a Petri dish containing test medium [Czapek agar (CZ) and yeast extract sucrose (YES)] (Davis et al., 1987). The plates were then incubated at $25^{\circ} \mathrm{C}$ for 4 days in the dark, and the presence or absence of fluorescence in the agar surrounding the growing Aspergillus colonies was determined by exposing the Petri dishes to UV light $(365 \mathrm{~nm})$, which was expressed as positive or negative.

\section{Detection of aflatoxins based on fluorescence}

The culture media used in these assays were PDA with sodium chloride, CZ and YES. Detection was performed at $25^{\circ} \mathrm{C}$ after 4 days in darkness. The presence or absence of fluorescence in the agar surrounding the colonies was determined under UV irradiation ( $365 \mathrm{~nm})$ and was expressed as positive or negative according to Franco et al. (1998).

\section{Determination of the toxigenic potential of $A$. flavus isolates}

Isolates were grown in sterilized SMKY liquid medium ( $20 \mathrm{~g}$ sucrose, $0.5 \mathrm{~g}$ magnesium sulfate, $3 \mathrm{~g}$ potassium nitrate and $7 \mathrm{~g}$ yeast extract in $1000 \mathrm{~mL}$ distilled water) (Davis et al., 1987). Flasks were inoculated with 6-mm diameter discs of $A$. flavus isolates at $25 \pm$ $2^{\circ} \mathrm{C}$ for 7 days (Paranagama et al., 2003). The experiments were performed in triplicate. After incubation, the contents of each flask were filtered through Whatman No. 1 filter paper. For AF extraction, the filtrates from each flask were treated three times with $50 \mathrm{~mL}$ chloroform using a separatory funnel. The chloroform extracts were then separately dehydrated with anhydrous sodium sulfate and evaporated to dryness in a water bath at $50^{\circ} \mathrm{C}$ under vacuum. The residues were dissolved in $10 \mathrm{~mL}$ methanol and stored in dark vials, and the extracts were passed through a $0.45-\mu \mathrm{m}$ micro-filter. Analysis of the compounds present in the specimens was performed using an HPLC apparatus (PerkinElmer series 200 UV/VIS) with a C18 column, $300 \mathrm{~mm}$ x $3.9 \mathrm{~mm}$ ID, $4-\mu \mathrm{m}$ particle size. The HPLC instrument was equipped with a UV detector, and fluorescence was measured using $365 \mathrm{~nm}$ excitation and $430 \mathrm{~nm}$ emission wavelengths. The mobile phase consisted of methanol: acetic acid: water $(20: 20: 60 \mathrm{v} / \mathrm{v} / \mathrm{v})$. The total run time for the separation was approximately $25 \mathrm{~min}$ at a flow rate of $1 \mathrm{~mL} / \mathrm{min}$ (Christian, 1990). 


\section{Extraction of DNA from A. flavus isolates}

A. flavus isolates were cultured in double layer media, consisting of a solid and a liquid layer, on 50-mm Petri dishes. The solid base medium was PDA, and the top liquid medium was peptone yeast glucose (PYG, $1200 \mu \mathrm{L}$ ). The fungi were incubated at $25^{\circ} \mathrm{C}$ for 2 days, after which the fungal mycelia $(50 \mathrm{mg}$ ) were scraped using slide covers and transferred to sterile Eppendorf tubes $(1.5 \mathrm{~mL})$ for DNA isolation. DNA was extracted from $50 \mathrm{mg}$ fresh mats according to Amer et al. (2011).

\section{RAPD PCR}

To identify the best primers for establishing the RAPD profile, we tested 6 primers from standard RAPD primer kits (Amersham Pharmacia) suppliers need locations using total DNA from A. flavus isolates as a template. The three primers with the highest reproducibility and clearest banding profiles, RAPD primers 1,3 , and 5 were selected. PCR amplifications were run using mixtures with a final volume of $25 \mu \mathrm{L}$ containing reaction buffer $(20 \mathrm{mM}$ Tris- $\mathrm{HCl}, \mathrm{pH} 8.4,50 \mathrm{mM} \mathrm{KCl})$ (Biolabs), $3.4 \mathrm{mM} \mathrm{MgCl}, 0.25 \mathrm{mM}$ dNTPs, $0.4 \mathrm{mM}$ of each primer, $2 \mathrm{U}$ Taq DNA polymerase (BioLabs), and $25 \mathrm{ng}$ genomic DNA (Williams et al., 1990). The amplification program consisted of an initial denaturation step at $95^{\circ} \mathrm{C}$ for $5 \mathrm{~min}$ (one cycle), followed by 45 cycles of denaturation at $95^{\circ} \mathrm{C}$ for $1 \mathrm{~min}$, annealing at $36^{\circ} \mathrm{C}$ for $1 \mathrm{~min}$ and amplification at $72^{\circ} \mathrm{C}$ for $2 \mathrm{~min}$, with a final extension at $72^{\circ} \mathrm{C}$ for $5 \mathrm{~min}$ (one cycle). Sequences of primers are listed in Table 1.

\begin{tabular}{llll}
\multicolumn{2}{l}{ Table 1. Sequences of the nucleotide primers used in this study. } \\
\hline Primer code & Sequence & RAPD primers & References \\
\hline RAPD primer 1 & 5'-GGT GCG GGA A-3' & Amplified region & Mahmoud et al., 2012 \\
RAPD primer 2 & 5'-GTT TCG CTC C-3' & $\begin{array}{l}\text { Fragments from 1-10 genomic sites } \\
\text { are amplified simultaneously }\end{array}$ & \\
RAPD primer 5 & 5'-AAC GCG CAA C-3' & ISSR primers & Batista et al., 2008 \\
Primer code & & Minisatellite-region DNA & \\
\cline { 2 - 4 }$(\text { GTG })_{5}$ & 5'-GTG GTG GTG GTG GTG-3' & & \\
$(\text { GACA })_{4}$ & 5'-GAC AGA CAG ACA GAC A-3' & & \\
$(\text { AGAG) })_{4}$ & 5'-AGA GAG AGA GAG AGA GG-3' & & \\
\hline
\end{tabular}

\section{ISSR PCR}

PCR amplification of ISSRs was performed with the primers $(\mathrm{GTG})_{5},(\mathrm{GACA})_{4}$ and $(\mathrm{AGAG})_{4} \mathrm{G}$. The reaction mixtures had a final volume of $25 \mu \mathrm{L}$ and contained reaction buffer (20 mM Tris-HCl, pH 8.4, $50 \mathrm{mM} \mathrm{KCl}$ (Biolabs), $1.5 \mathrm{mM} \mathrm{MgCl}, 0.25 \mathrm{mM}$ dNTPs, $0.25 \mathrm{mM}$ primers, $1.25 \mathrm{U}$ Taq DNA polymerase (BioLabs), and $25 \mathrm{ng}$ genomic DNA. The amplification program consisted of an initial denaturation step at $93^{\circ} \mathrm{C}$ for $5 \mathrm{~min}$, followed by 40 cycles of denaturation at $93^{\circ} \mathrm{C}$ for $20 \mathrm{~s}$, annealing at $55^{\circ} \mathrm{C}$ for $45 \mathrm{~s}$ and amplification at $72^{\circ} \mathrm{C}$ for $90 \mathrm{~s}$, with a final extension at $72^{\circ} \mathrm{C}$ for 6 min. Sequences of primers are listed in Table 1.

\section{DNA electrophoresis}

For all samples, the amplified DNA $(15 \mu \mathrm{L})$ was electrophoresed using an electrophoresis unit (Wide Mini-Sub-Cell GT, Bio-RAD) in 2\% agarose containing ethidium bromide 
$(0.5 \mu \mathrm{g} / \mathrm{mL})$ at constant $75 \mathrm{~V}$ and $60 \mathrm{~mA}$ and was visualized with a UV trans-illuminator.

\section{Gel analysis of DNA}

The DNA gel was scanned for band Rf using a gel documentation system (AAB Advanced American Biotechnology, Fullerton, CA, USA). The different molecular weights of the bands were determined against a DNA standard (kb DNA ladder, Stratagene, Canada) with molecular weights of 100, 200, 300, 400, 500, 600, 700, 800, 900, 1000, and $1500 \mathrm{bp}$. The similarity level was determined by unweighted pair group method with arithmetic mean (UPGMA).

\section{RESULTS}

\section{Frequency percentage of isolated fungi in corn grains from Riyadh, Dammam, and Abha regions}

Frequency of the fungi isolated from wheat grains from the Riyadh, Dammam, and Abha regions of Saudi Arabia. Twelve species from six fungal genera were identified from the samples tested (Table 2). In the Riyadh region, A. flavus, Fusarium moniliforme, and F. oxysporum were the dominant fungi isolated from wheat grains, showing frequencies of 20.00 , 12.00 , and $12.00 \%$, respectively. The other isolated fungi occurred at frequencies ranging from 0.00 to $8.00 \%$. In the Dammam region, A. flavus, A. niger, and F. moniliforme were the dominant fungi isolated from the wheat grains, displaying frequencies of $17.90,14.30$, and $14.30 \%$, respectively. The other isolated fungi were present at frequencies ranging from 3.6 to $10.70 \%$. In the Abha region, A. flavus, F. moniliforme and F. oxysporum were the dominant fungi isolated from the wheat grains, exhibiting frequencies of $29.20,11.80$ and $11.80 \%$, respectively. The other isolated fungi occurred at frequencies ranging from 0.00 to $5.90 \%$. A . $\mathrm{Ala}$ vus isolates represented the dominant fungi in these three regions, with five $A$. flavus isolates being obtained from each region.

Table 2. Frequency of fungi isolated from corn kernels from Riyadh, Dammam, and Abha regions in Saudi Arabia.

\begin{tabular}{lrrr}
\hline Isolated fungi & Riyadh & Dammam & Abha \\
\hline Aspergillus flavus & 20.00 & 17.90 & 29.20 \\
A. niger & 8.00 & 14.30 & 5.90 \\
A. parasiticus & 4.00 & 3.60 & 0.00 \\
Alternaria longipes & 8.00 & 7.10 & 5.90 \\
A. chlamydospora & 4.00 & 3.60 & 5.90 \\
Fusarium moniliforme & 12.00 & 14.30 & 11.80 \\
F. oxysporum & 12.00 & 10.70 & 11.80 \\
F. solani & 8.00 & 7.10 & 0.00 \\
Penicillium funiculosum & 8.00 & 7.10 & 5.90 \\
P. implicatum & 0.00 & 3.60 & 5.90 \\
Eupenicillium alutaceum & 8.00 & 7.10 & 1.90 \\
Rhizopus stolonifer & 8.00 & 3.60 & 1.80 \\
Total & 100.00 & 100.00 & 100.00 \\
\hline
\end{tabular}

\section{Detection of aflatoxigenic $A$. flavus isolates under UV irradiation $(365 \mathrm{~nm})$}

Three different culture media, CZ, PDA, and YES agar, were used to screen for AF 
production. The production of AF was readily detectable by direct visualization of a beige ring surrounding the colonies after 4 days of incubation. The presence or absence of fluorescence in the agar surrounding the colonies was determined under UV irradiation (365 nm) and was expressed as positive or negative. The data presented in Table 3 show that fifteen isolates of $A$. flavus were positive for AF production, and that four A. flavus isolates were negative. Example of non-aflatoxigenic and aflatoxigenic isolates are shown in Figure 2.

Table 3. Detection of aflatoxigenic Aspergillus flavus isolates under UV radiation (365 nm).

\begin{tabular}{|c|c|c|c|}
\hline \multirow[t]{2}{*}{ A. flavus code } & \multicolumn{3}{|c|}{ Medium } \\
\hline & $\mathrm{PDA}+\mathrm{NaCl}$ & Czapek & YES \\
\hline \multicolumn{4}{|l|}{ Riyadh region } \\
\hline $\mathrm{C} 1$ & + & + & + \\
\hline $\mathrm{C} 2$ & - & + & + \\
\hline $\mathrm{C} 3$ & - & + & - \\
\hline $\mathrm{C} 4$ & - & + & - \\
\hline $\mathrm{C} 5$ & - & + & + \\
\hline \multicolumn{4}{|c|}{ Dammam region } \\
\hline C6 & - & + & + \\
\hline $\mathrm{C} 7$ & - & - & - \\
\hline $\mathrm{C} 8$ & + & + & + \\
\hline C9 & - & + & + \\
\hline $\mathrm{C} 10$ & - & - & - \\
\hline \multicolumn{4}{|l|}{ Abha region } \\
\hline $\mathrm{C} 11$ & - & - & - \\
\hline $\mathrm{C} 12$ & + & + & + \\
\hline $\mathrm{C} 13$ & - & - & + \\
\hline C14 & - & - & - \\
\hline $\mathrm{C} 15$ & - & - & - \\
\hline
\end{tabular}

Czapeks $=$ Czapeks Dox agar; YES $=$ yeast extract sucrose agar; PDA = potato dextrose agar.

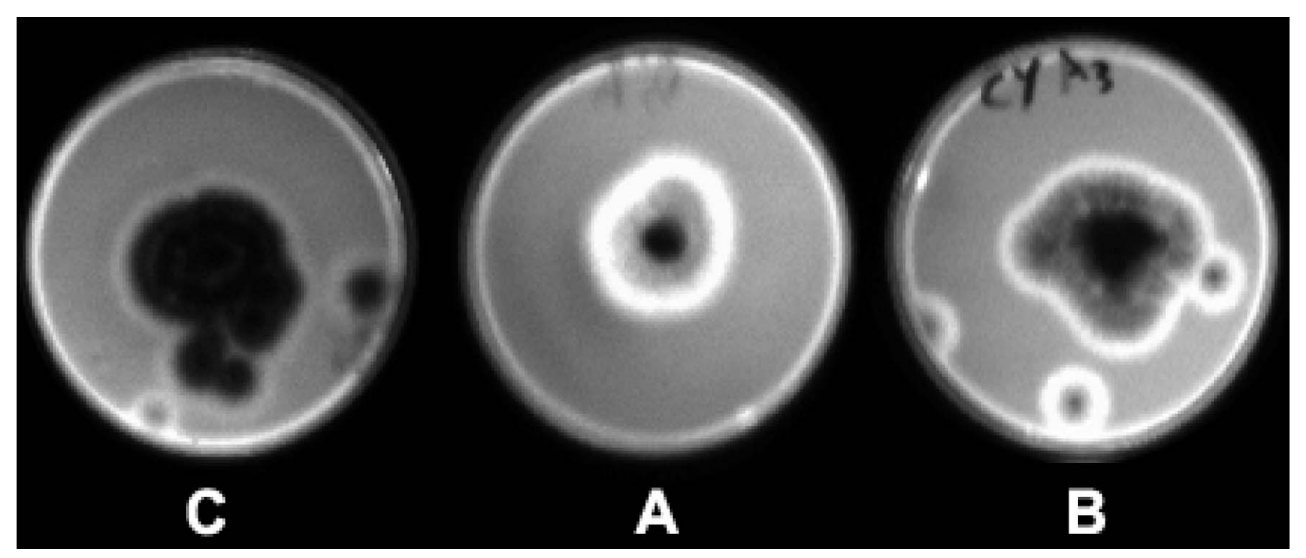

Figure 2. Non-aflatoxigenic isolate of Aspergillus flavus (C), two aflatoxigenic isolates (A) and (B) visualized under 365-nm UV light. The white ring around colonies of aflatoxigenic isolates displays faint blue or green fluorescence.

\section{Aflatoxin production}

Fifteen isolates were capable of producing detectable levels of both B and G AF, 
whereas six isolates failed to produce a detectable amount of the toxins. The highest levels of $\mathrm{B} 1$ and $\mathrm{B} 2$ (2.9 and $2.3 \mathrm{ppb})$ were obtained from isolate $\mathrm{C} 8$. Isolate $\mathrm{C} 3$ showed the highest production of G1 (1.9 ppb), whereas isolate $\mathrm{C} 1$ exhibited the highest production of G2 (1.6 ppb) (Table 4).

\begin{tabular}{|c|c|c|c|c|}
\hline \multirow[t]{2}{*}{ A. flavus code } & \multicolumn{4}{|c|}{ Aflatoxin (ppb) } \\
\hline & B1 & B2 & G1 & G2 \\
\hline \multicolumn{5}{|l|}{ Riyadh region } \\
\hline $\mathrm{C} 1$ & 2.6 & 2.1 & 1.7 & 1.6 \\
\hline $\mathrm{C} 2$ & 1.8 & 1.5 & 0.9 & 1.1 \\
\hline $\mathrm{C} 3$ & 2.8 & 2.2 & 1.9 & 1.2 \\
\hline $\mathrm{C} 4$ & 0.0 & 0.0 & 0.0 & 0.0 \\
\hline $\mathrm{C} 5$ & 2.1 & 1.8 & 1.5 & 1.2 \\
\hline \multicolumn{5}{|c|}{ Dammam region } \\
\hline C6 & 2.3 & 2.1 & 0.9 & 0.7 \\
\hline C7 & 0.0 & 0.0 & 0.0 & 0.0 \\
\hline $\mathrm{C} 8$ & 2.9 & 2.3 & 1.6 & 1.3 \\
\hline C9 & 2.5 & 2.1 & 1.7 & 1.5 \\
\hline $\mathrm{C} 10$ & 0.0 & 0.0 & 0.0 & 0.0 \\
\hline \multicolumn{5}{|l|}{ Abha region } \\
\hline C11 & 0.0 & 0.0 & 0.0 & 0.0 \\
\hline $\mathrm{C} 12$ & 1.4 & 1.1 & 0.9 & 0.7 \\
\hline $\mathrm{C} 13$ & 1.8 & 1.3 & 1.0 & 0.8 \\
\hline C14 & 0.0 & 0.0 & 0.0 & 0.0 \\
\hline C15 & 0.0 & 0.0 & 0.0 & 0.0 \\
\hline
\end{tabular}

\section{Chemotype patterns}

The A. flavus isolates were classified into two chemotypes on the basis of their ability to produce B1, B2, G1, and G2 (Table 5). Chemotype I was the prominent group and included eight isolates (aflatoxigenic), comprising $53.3 \%$ of the isolates obtained. Chemotype II included seven isolates (non-aflatoxigenic), corresponding to $46.7 \%$ of the isolates.

Table 5. Chemotype patterns of Aspergillus flavus isolated from corn kernels based on the ability to produce
AFs B1, B2, G1, and G2.
\begin{tabular}{lcccccc}
\hline Chemotype & \multicolumn{7}{c}{ Aflatoxin } \\
\cline { 2 - 6 } & B1 & B2 & G1 & G2 & No. of isolates (\%) \\
\hline I & + & + & + & + & $8(53.3)$ \\
II & - & - & - & - & $7(46.7)$ \\
\hline
\end{tabular}

\section{Genetic characterization of $A$. flavus isolates}

Genetic characterization was evaluated by PCR amplification using a set of 6 primers (3 RAPD and 3 ISSR). The amplification products were analyzed for polymorphisms by gel electrophoresis to determine whether pathotypes could be distinguished at the molecular level. 


\section{RAPD profiles}

\section{Phenetic analysis using three RAPD primers}

\section{Phenetic analysis of the 15 A. flavus isolates based on RAPD primer 1}

The dendrogram generated using the similarity matrix produced from the banding patterns obtained with primer 1 exhibited two main clusters, with $63.82 \%$ genetic similarity (GS) (Figure 3). The GSs between the isolates tested ranged from $63.82-98.42 \%$. The first main cluster included two groups with $74.13 \%$ GS. The first group contained Abha region isolates $\mathrm{C} 12$, C15, C13, and C14, which showed $85.03 \%$ GS. The second group consisted of only one isolate, $\mathrm{C} 8$ from the Dammam region. The second main cluster included two groups with $83.44 \%$ GS. The first group comprised isolates C3 from the Riyadh region and C7 from the Dammam region, which displayed $91.61 \%$ GS. The second group contained two subgroups and displayed $89.10 \%$ GS. The first subgroup included only one isolate, C11 from the Dammam region, and the second subgroup was divided into two subclusters, with $90.16 \%$ GS. The first subcluster consisted of isolates $\mathrm{C} 2, \mathrm{C} 4$, and $\mathrm{C} 5$ from the Riyadh region and C6 and C9 from the Dammam region, with $93.60 \%$ GS being detected between isolates. The second subcluster included isolate $\mathrm{C} 1$ from the Riyadh region and isolate $\mathrm{C} 10$ from the Dammam region, which showed $94.51 \%$ GS.

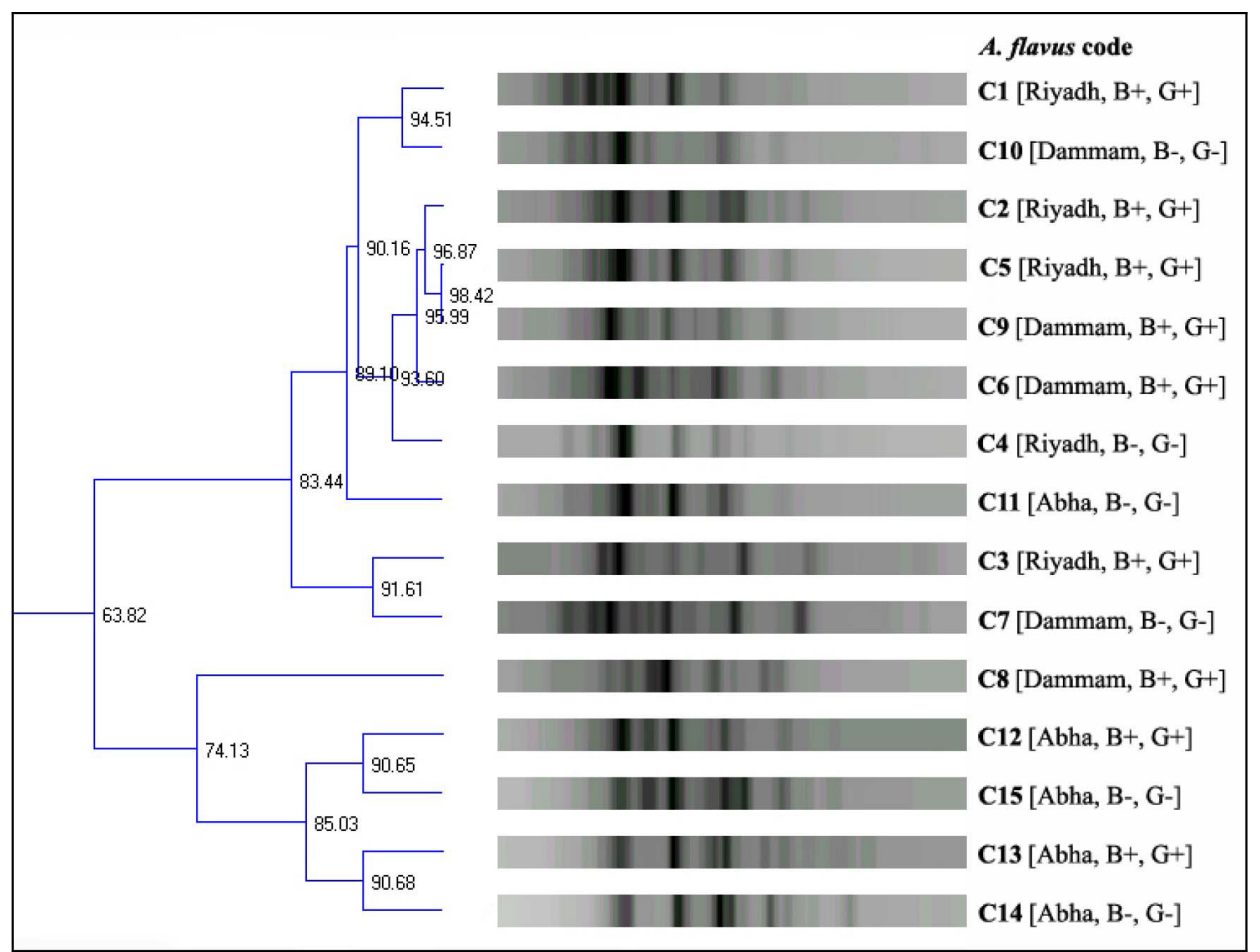

Figure 3. Dendrogram obtained by UPGMA method derived from PCR-amplification banding of RAPD with RAPD primer 1 of 15 Aspergillus flavus isolates. 
These data indicated that this primer was not able to differentiate between isolates according to geographic regions, except for the Abha region, i.e., isolates $\mathrm{C} 12, \mathrm{C} 13, \mathrm{C} 14$, and C15, which exhibited $85.03 \%$ GS and were located in a single subcluster.

The four subclusters included eight isolates. The four AFB and AFG-producing isolates $(\mathrm{C} 1, \mathrm{C} 3, \mathrm{C} 12$, and $\mathrm{C} 13)$ and the four isolates that did not produce $\mathrm{AFB}$ or $\mathrm{AFG}(\mathrm{C} 7, \mathrm{C} 10$, $\mathrm{C} 14$, and $\mathrm{C} 15)$ from different regions resided in two main clusters, with a random distribution. All of the subclusters included a combination of aflatoxigenic and non-aflatoxigenic isolates. For example, one subcluster included isolates $\mathrm{C} 10$ (non-AFBand AFG-non-producing) and C1 (AFB and AFG-producing) and showed $94.51 \%$ GS. No correlation was detected between the DNA banding patterns obtained and AF-producing ability.

\section{Phenetic analysis of the 15 A. flavus isolates based on RAPD primer 3}

The dendrogram generated using the similarity matrix produced from the banding patterns obtained with primer 3 exhibited two main clusters, with $50.35 \%$ GS (Figure 4). The GS between the isolates tested ranged 50.35-96.07\%. The first main cluster included two isolates from the Abha region, $\mathrm{C} 11$ and $\mathrm{C} 12$, which showed $74.31 \%$ GS. The second main cluster contained two groups with $50.87 \%$ GS. The first group included only one isolate, C10, from the Dammam region, while the second group was divided into two subgroups, which showed $74.81 \%$ GS. The first subcluster included isolates $\mathrm{C} 2, \mathrm{C} 3$, and $\mathrm{C} 4$ from the Riyadh region, $\mathrm{C} 6, \mathrm{C} 7, \mathrm{C} 8$, and $\mathrm{C} 9$ from the Dammam region, and $\mathrm{C} 14$ from the Abha region, with $75.88 \%$ GS being detected between these isolates. The second subcluster included isolates $\mathrm{C} 1$ and $\mathrm{C} 5$ from the Riyadh region and $\mathrm{C} 13$ and $\mathrm{C} 15$ from the Abha region, which showed $84.52 \%$ GS. The isolates representing the Dammam region, i.e., isolates $\mathrm{C} 6, \mathrm{C} 7$, and $\mathrm{C} 9$, showed GS greater than $92 \%$. The isolate pairs $\mathrm{C} 13+$ $\mathrm{C} 15$ and $\mathrm{C} 11+\mathrm{C} 12$ from the Abha region showed GS of 91.63 and $79.31 \%$, respectively.

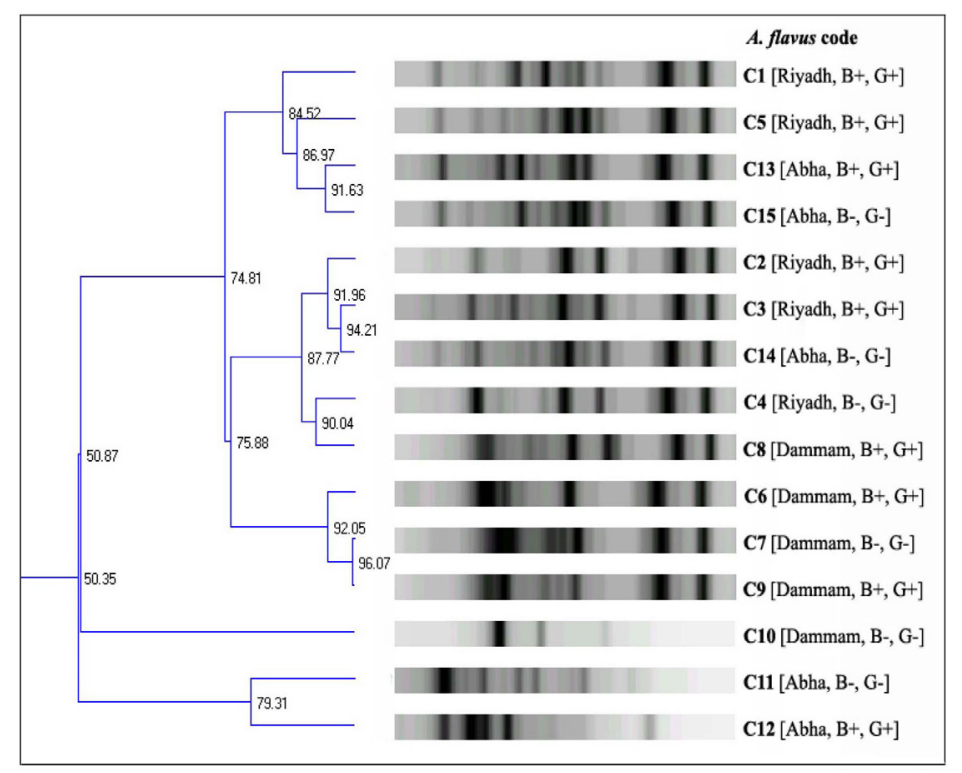

Figure 4. Dendrogram obtained by UPGMA method derived from PCR-amplification banding of RAPD with RAPD primer 3 of 15 Aspergillus flavus isolates. 
These findings indicated that that this primer was, to some extent, able to differentiate between regions. With reference to this primer, there was a partial relationship detected between the clustering observed in the RAPD dendrogram and the geographic origin of the isolates tested.

The five subclusters obtained included ten isolates. The five AFB and AFG-producing isolates $(\mathrm{C} 13, \mathrm{C} 3, \mathrm{C} 8, \mathrm{C}$, and $\mathrm{C} 12)$ and the five non-AFB- or non-AFG-producing isolates $(\mathrm{C} 15, \mathrm{C} 14, \mathrm{C} 4, \mathrm{C} 7$, and $\mathrm{C} 11)$ came from different regions and resided in the two main clusters with a random distribution.

All subclusters included a combination of aflatoxigenic and non-aflatoxigenic isolates. For example, one subcluster included isolates C14 (non-AFB and AFG non-producing) and C3 (AFB and AFG producing), which showed 94.21\% GS. No correlation was detected between the DNA banding patterns obtained and the AF-producing ability.

\section{Phenetic analysis of the 15 A. flavus isolates based on RAPD primer 5}

The dendrogram generated using the similarity matrix produced with the banding patterns obtained with primer 5 showed the formation of two main clusters, with $49.75 \%$ GS (Figure 5). The GS between the isolates tested ranged 49.75-98.65\%. The first main cluster included two isolates, $\mathrm{C} 11$ and $\mathrm{C} 12$ from the Abha region, which displayed $79.19 \%$ GS. The second main cluster included two groups, with $71.69 \%$ GS. The first group was divided into two subclusters, which showed $84.51 \%$ GS. The first subcluster included only one isolate, C6, from the Dammam region, and the second included isolates from both the Riyadh region (C5) and the Abha region (10.13 and 15), with $85.42 \%$ GS. The second group was divided into two subclusters, with $88.45 \%$ GS. The first subcluster included isolates C8 and C9 from the Dammam region and isolate $\mathrm{C} 14$ from the Abha region, which showed $92.41 \% \mathrm{GS}$, while the second included isolates $\mathrm{C} 1, \mathrm{C} 2, \mathrm{C} 3$, and $\mathrm{C} 4$ from the Riyadh region and $\mathrm{C} 7$ from the Dammam region, which displayed $92.93 \%$ GS. The isolates representing the Riyadh region, i.e., isolates $\mathrm{C} 1, \mathrm{C} 7$, $\mathrm{C} 3$, and $\mathrm{C} 4$, exhibited GS greater than 96\%, while isolates C8 and 9 from the Dammam region and isolates $\mathrm{C} 13$ and $\mathrm{C} 15$ from the Abha region showed GS of 93.80 and $91.69 \%$, respectively.

These findings indicated that this primer was, to some extent, able to differentiate between regions. With reference to this primer, there was a partial relationship found between the clustering observed in the RAPD dendrogram and the geographic origin of the isolates tested.

The three subclusters included six isolates. The three AFB and AFG-producing isolates $(\mathrm{C} 1, \mathrm{C} 4$, and $\mathrm{C} 12)$ and the three non-AFB or non-AFG-producing isolates $(\mathrm{C} 7, \mathrm{C} 3$, and $\mathrm{C} 10)$ came from different regions and resided within the two main clusters, with a random distribution.

All subclusters included a combination of aflatoxigenic and non-aflatoxigenic isolates. For example, one subcluster included isolate C4 (non-AFB- and AFG-non-producing) and C3 (AFB- and AFG-producing), which showed 99.40\% GS. No correlation was detected between the DNA banding patterns obtained and the AF-producing abilities of the isolates.

\section{Phenetic analysis based on three ISSR primers}

\section{Phenetic analysis of 15 A. flavus isolates based on ISSR primer (GTG),}

The dendrogram generated using the similarity matrix produced with the banding patterns obtained from the $(\mathrm{GTG})_{5}$ primer showed the formation of two main clusters, with $65.19 \%$ GS (Figure 6). The GS between the isolates tested ranged 65.19-99.22\%. The first 
main cluster included one isolate, $\mathrm{C} 2$, from the Riyadh region. The second main cluster included two groups, with $75.27 \%$ GS. The first group included isolates $\mathrm{C} 11$ and $\mathrm{C} 12$ from the Abha region, which displayed $97.31 \%$ GS. The second group was divided into two subclusters, exhibiting $81.22 \%$ GS. The first subcluster included isolates C3 and C5 from the Riyadh region, with $97.17 \% \mathrm{GS}$. The second subcluster comprised ten isolates: $\mathrm{C} 1$ and $\mathrm{C} 4$ from the Riyadh region, C6, C7, C8, C9, and C10 from the Dammam region and C13, C14, and C15 from the Abha region, which showed $81.56 \%$ GS.

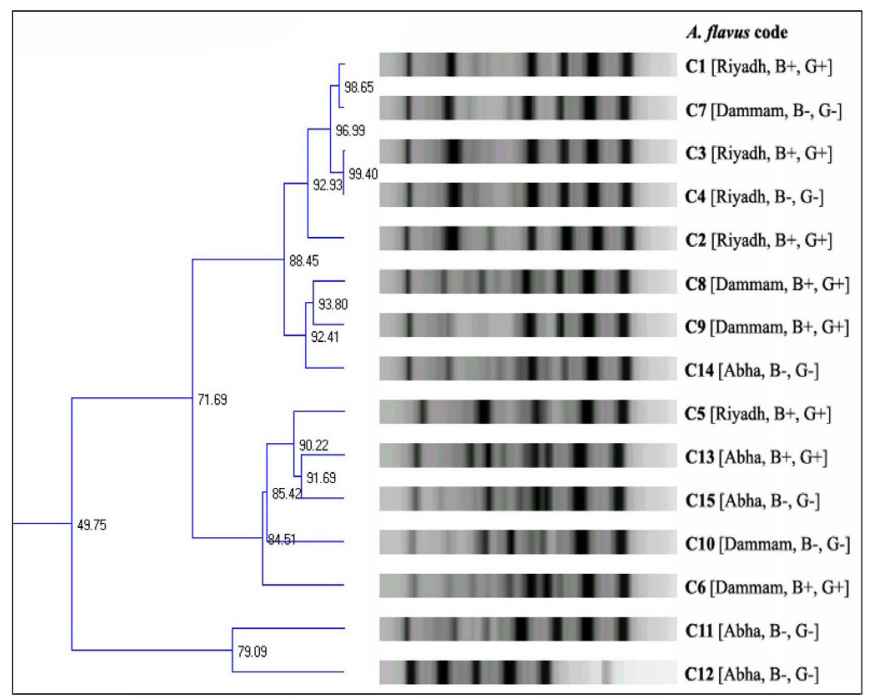

Figure 5. Dendrogram obtained by UPGMA method derived from PCR-amplification banding of RAPD with RAPD primer 5 of 15 Aspergillus flavus isolates.

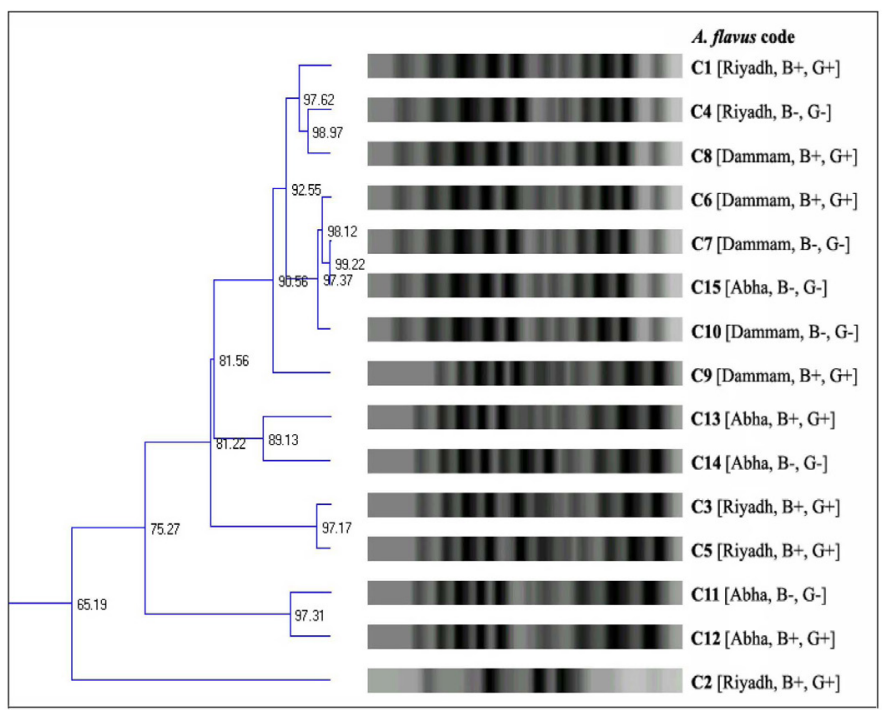

Figure 6. Dendrogram obtained by UPGMA method derived from PCR-amplification banding of ISSR with primer $(\mathrm{GTG})_{5}$ of 15 Aspergillus flavus isolates. 
With regard to this primer, there was no relationship found between the clustering observed in the ISSR dendrogram and the geographic origin of the isolates tested.

The three subclusters included six isolates. The three AFB- and AFG-producing isolates $(\mathrm{C} 8, \mathrm{C} 12$, and $\mathrm{C} 13)$ and the three non-AFB- or non-AFG-producing isolates $(\mathrm{C} 4, \mathrm{C} 10$, and $\mathrm{C} 14$ ) from different regions resided in the two main clusters with a random distribution.

All subclusters included a combination of aflatoxigenic and non-aflatoxigenic isolates. For example, one subcluster included isolates C4 (non-AFB- and non-AFG-producing) and C8 (AFB- and AFG-producing), showing 98.97\% GS. No correlation was found between the DNA banding patterns obtained and the AF-producing ability of the isolates. One subcluster included isolates $\mathrm{C} 7$ and $\mathrm{C} 15$, which were $\mathrm{AFB}$ and $\mathrm{AFG}$ non-producers and showed $99.22 \%$ GS.

\section{Phenetic analysis of the 15 A. flavus isolates based on ISSR primer (GACA),}

The dendrogram generated using the similarity matrix produced with the banding patterns obtained with the (GAGA) ${ }_{4}$ primer exhibited two main clusters, with $80.37 \%$ GS (Figure 7). The GS between the isolates tested ranged $80.37-99.52 \%$. The first main cluster included only one isolate, $\mathrm{C} 2$, from the Riyadh region, and the second main cluster included two groups, showing $81.99 \%$ GS. The first group was divided into two subclusters, displaying $92.83 \%$ GS. The first subcluster included isolates C11, C12, C13, C14, and C15 from the Abha region, with $97.53 \% \mathrm{GS}$, and the second subcluster comprised only one isolate, C5, from the Riyadh region. The second group was divided into two subclusters, exhibiting $92.48 \%$ GS. The first subcluster contained only one isolate, $\mathrm{C} 4$, from the Riyadh region, and the second subcluster contained isolates $\mathrm{C} 1$ and $\mathrm{C} 3$ from the Riyadh region and $\mathrm{C} 7, \mathrm{C} 8, \mathrm{C} 9$, and $\mathrm{C} 10$ from the Dammam region.

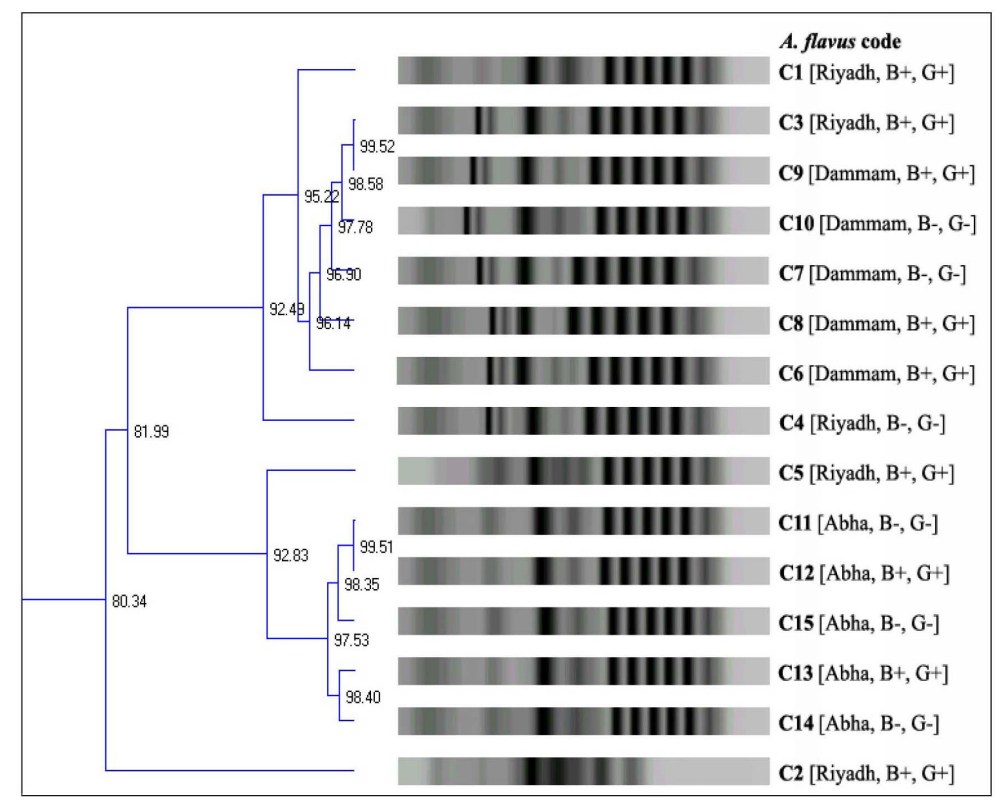

Figure 7. Dendrogram obtained by UPGMA method derived from PCR-amplification banding of ISSR with primer (GACA) ${ }_{4}$ of 15 Aspergillus flavus isolates. 
In reference to this primer, there was a strong relationship found between the clustering observed in the ISSR dendrogram and the geographic origin of the isolates tested, especially with the Abha region isolates and the Dammam region isolates.

The three subclusters included seven isolates. The four AFB and AFG-producing isolates $(\mathrm{C} 3, \mathrm{C} 9, \mathrm{C} 12$, and $\mathrm{C} 13)$ and three non-AFB or AFG-producing isolates $(\mathrm{C} 10, \mathrm{C} 11$, and $\mathrm{C} 14)$ came from different regions and resided in the two main clusters with a random distribution. All subclusters included a combination of aflatoxigenic and non-aflatoxigenic isolates. For example, one subcluster contained isolate $\mathrm{C} 11$ (non-AFB and AFGnon-producing) and C12 (AFB and AFG producing), which showed $99.51 \%$ GS. No correlation was detected between the DNA banding patterns obtained and the AF-producing ability of the isolates.

\section{Phenetic analysis of 15 A. flavus isolates based on ISSR primer $(A G A G)_{4} G$}

The dendrogram generated using the similarity matrix produced from the banding patterns obtained with primer (AGAG) ${ }_{4} \mathrm{G}$ showed two main clusters, with $67.27 \%$ GS (Figure 8). The GS between the isolates tested ranged $67.27-99.49 \%$. The first main cluster included only isolate C9, from the Dammam region, and the second main cluster included two groups, with $78.75 \%$ GS. The first group was divided into two subclusters, which showed $82.92 \%$ GS. The first subcluster comprised isolates C6, C7, and C8 from the Dammam region and isolates C11, $\mathrm{C} 12, \mathrm{C} 13, \mathrm{C} 14$, and $\mathrm{C} 15$ from the Abha region, and the second subcluster included two isolates, $\mathrm{C} 4$, and $\mathrm{C} 10$, from the Riyadh and Dammam regions, with $92.25 \%$ GS. The second group included isolates $\mathrm{C} 1, \mathrm{C} 2, \mathrm{C} 3$, and C5 from the Riyadh region, which displayed 95.40\% GS.

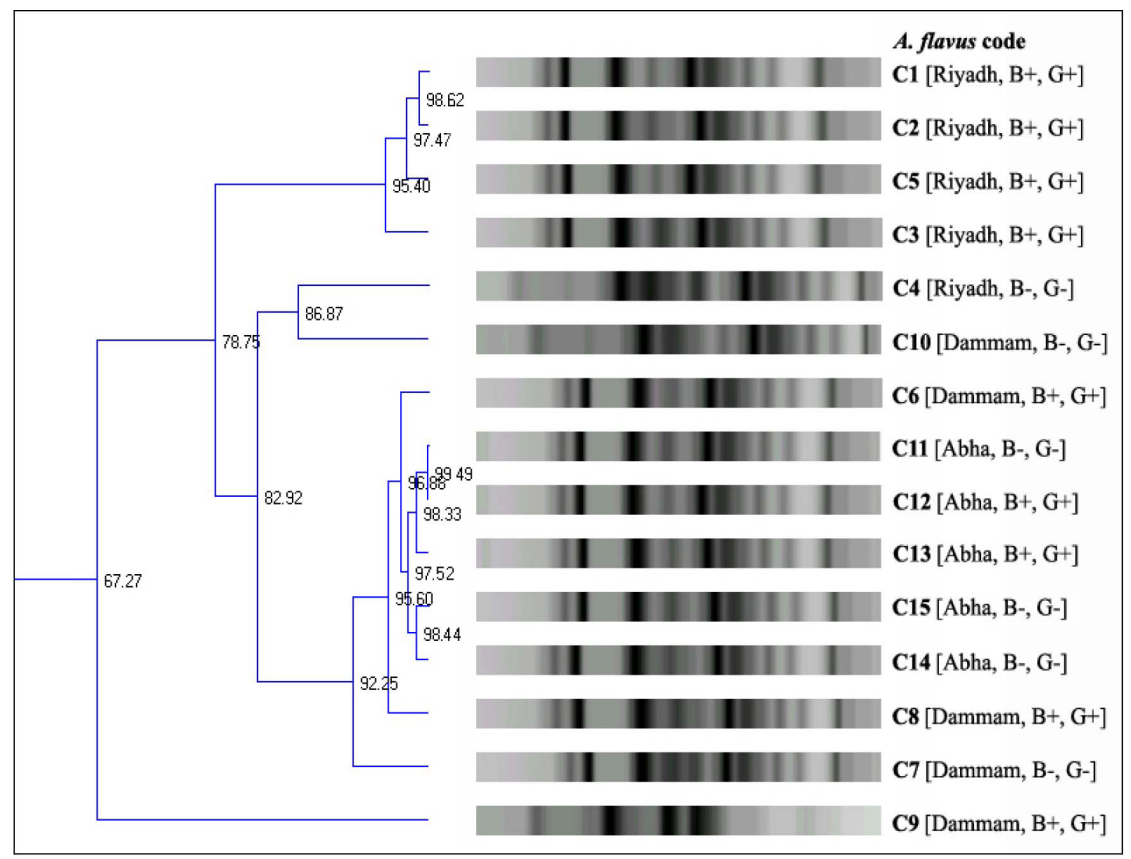

Figure 8. Dendrogram obtained by UPGMA method derived from PCR amplification banding of ISSR with primer (AGAG) ${ }_{4} \mathrm{G}$ of 15 Aspergillus flavus isolates. 
With regard to this primer, there was a strong relationship detected between the clustering observed in the ISSR dendrogram and the geographic origin of the isolates tested, especially for the Riyadh region isolates and the Abha region isolates.

The four subclusters included eight isolates. One subcluster included isolates $\mathrm{C} 1$ and C2 (AFB or AFG-producing), with $98.62 \%$ GS. The first subcluster included C4 and C10 (non-AFB and AFG non-producing), which showed $86.87 \% \mathrm{GS}$, and the second subcluster included $\mathrm{C} 15$ and $\mathrm{C} 14$ (non-AFB and AFG-non-producing), displaying 98.44\% GS. Another subcluster included isolates C12 (AFB and AFG-producing) and C11 (non-AFB and AFG non-producing), with $99.49 \%$ GS. There was a strong relationship detected between the clustering observed in the ISSR dendrogram and the AF-producing ability of the isolates.

\section{DISCUSSION}

In the corn samples examined, the isolation frequency among the fungal genera was the highest for Aspergillus, followed by Penicillium and Fusarium, and the lowest for Alternaria. $P$. verrucosum was the most frequently isolated species, followed by $A$. niger aggregates, A. ochraceus, A. flavus, $P$. chrysogenum, A. parasiticus, A. carbonarius, and Fusarium and Alternaria spp. Abd El-Aziz Abeer et al. (2012) and Mahmoud et al. (2013) reported A. flavus as the predominant species isolated from maize grains in Saudi Arabia. Gao et al. (2007) isolated Aspergilli as the predominant species in China, followed by Penicillium, Fusarium, and other fungi. A predominance of Aspergillus species, followed by Fusarium species, has also been reported from maize silage in Argentina (González et al., 2008).

The prevalence of $\mathrm{AF}$ production, determined by the fluorescence of fungal colonies and recorded as the percentage of positive isolates observed in the $\mathrm{PDA}+\mathrm{NaCl}, \mathrm{CZ}$, and $\mathrm{YES}$ agar media, was 20,60 , and $53.33 \%$, respectively. AF are produced by some isolates of $A$. flavus, but not all isolates were able to produce $\mathrm{AF}$, which has encouraged screening for $\mathrm{AF}$ production abilities based on the fact that aflatoxigenic isolates produce blue fluorescence on the reverse side of colonies under UV light, whereas non-aflatoxigenic strains do not fluoresce (Davis et al., 1987). A new, reliable, fast, simple method for the detection of aflatoxigenic $\mathrm{As}$ pergillus strains involves the addition of a cyclodextrin to the common media used for testing isolates for $\mathrm{AF}$ production to enhance the natural fluorescence of AF. Colonies of Aspergillus produce a bright yellow-orange pigment, and blue (B1, B2) or green $(\mathrm{G} 1, \mathrm{G} 2)$ fluorescent halos appear around aflatoxigenic colonies upon exposition to UV light (Fente et al., 2001).

The 15 A. flavus isolates described in this study were classified into two major chemotypes, where chemotype I included AF producers (53.3\%) and chemotype II included AF non-producers (46.7\%). HPLC determination of AF is sensitive and accurate in unprocessed cereals and cereal-based products (Pascale, 2009). Several authors have applied HPLC methods for low-ppb detection of AF (B1, B2, G1, and G2) and AF residues in cereals. Ahsan et al. (2009) found that of the 40 maize samples examined, 34 were contaminated with AF in Pakistan. The presence of AF (B1, B2, G1, and G2) was determined by RP-HPLC, and the mean values of B1and B2 were $(10-46 \mu \mathrm{g} / \mathrm{kg})$ and G1 and G2 were $(0.2-12 \mu \mathrm{g} / \mathrm{kg})$. Yassin et al. (2012) found that most of the Aspergilli isolated from corn grains produced in Saudi Arabia were toxigenic and varied in the type and quantity of AF. B1 was generally the most dominant toxin, especially from A. flavus. Three isolates of $A$. flavus produced $\mathrm{B} 1$ in concentrations ranging from 2 to $8 \mathrm{ppb}$, whereas two isolates produced $\mathrm{B} 2$ at concentrations ranging from 1 to $2 \mathrm{ppb}$. Three isolates produced G1 in concentrations ranging from 2 to $4 \mathrm{ppb}$, and two 
isolates produced G2 in concentrations ranging from 1 to $3 \mathrm{ppb}$. Martins et al. (2008) detected and quantified AF using HPLC in Portugal. Five isolates of A. flavus produced B1, B2, G1 and G2. The concentrations detected for B1, B2, G1, and G2 ranged from 18-24, 6-18, 9-12, and $6-8 \mathrm{mg} / \mathrm{kg}$, respectively. Rocha et al. (2009) reported that among 200 corn samples analyzed, $21(10.5 \%)$ were contaminated with B1, seven $(3.5 \%)$ with B2 and only one $(0.5 \%)$ with G1 and G2. Sixteen $(76.2 \%)$ of the 21 positive samples showed a total AF $(B 1+B 2+G 1+G 2)$ concentration that was higher than the limit established by Brazilian regulations $(20 \mu \mathrm{g} / \mathrm{kg})$.

All of the RAPD primers employed in the present study were able to reveal information contributing to genetic characterization for the isolates as well as determination of their genetic diversity. Regarding the geographic sources of the isolates, two relationships were found: first, there was no apparent correlation observed for primer RAPD 1; second, there was a partial relationship observed for RAPD primers 3 and 5 with the RAPD dendrogram, but no correlation was detected between the RAPD dendrogram and the AF-producing ability of the isolates. Batista et al. (2008) used RAPD molecular markers with the aim of genetically characterizing the diversity of $A$. flavus strains. High genetic diversity was revealed by their RAPD analysis, and a high efficiency of strain characterization was achieved. The characterization of seven different Aspergillus species by RAPD was useful for estimating the distances between and within species and may contribute to future management and conservation programs. Their results indicated that the genetic differences between Aspergillus species maintained genetic diversity within this population (Irshad and Nawab, 2012). RAPD was also used for the analysis of 14 isolates of A. flavus from two geographically distinct sites in Brazil. The distribution of the isolates showed a non-random pattern, though it cannot be assumed that this is a fully discriminatory result, and thus, the utility of RAPD analysis is debatable (Lourenço et al., 2007). Similar findings have been reported by Tran-Dinh et al. (1999). Twenty-one isolates of Rhizoctonia solani were characterized by RAPD-PCR. There was a partial relationship found between the genetic similarity of the isolates and the recorded AF, level of virulence or geographic origin based on the RAPD dendrogram obtained (Mahmoud et al., 2012). Other authors have reported detecting no correlation between DNA banding profiles and the production or nonproduction of AF (Tran-Dinh et al., 1999; Lourenço et al., 2007; Sepahvand et al., 2011). However, in one investigation involving isolates of Aspergillus section flavi based on RAPD analysis, Egel et al. (1994) grouped strains with similar toxigenic capacities in a manner that allowed more subtle differentiation compared to the simple classification of toxin producers and non-producers. Because the RAPD-PCR technique amplifies random fragments of the fungal genome, the fragments that contain the genes regulating toxin production may not have been amplified using this technique with the primers selected. Similar results have been described in other studies with Aspergillus spp that have shown no correlation between DNA banding profiles and the production or non-production of mycotoxins (Gashgari et al., 2010).

All ISSR primers used in the present study contributed to the genetic characterization of the diversity of the isolates. With respect to the geographic sources of the isolates, two relationships were found: first, there was no apparent correlation with primer (GTG), and second, there was a strong correlation observed for primers (GACA) $)_{4}$ and $(\mathrm{AGAG})_{4} \mathrm{G}$ with the ISSR dendrogram, whereas there was no correlation between the ISSR dendrogram and AF-producing ability of the isolates found when using the primers (GTG) ${ }_{5}$ and (GACA) ${ }_{4}$. There was a strong correlation for primer $(\mathrm{AGAG})_{4} \mathrm{G}$. No apparent correlation was found between the ISSR dendrogram and AF-producing ability based on primers (GTG) and (GACA), whereas a strong correlation was found using primer $(\mathrm{AGAG})_{4}$. ISSR microsatellite markers have been 
employed to characterize A. flavus isolates in a wheat crop. ISSR analysis can be useful in population genetic analyses, epidemiological surveys and ecological studies of $A$. flavus. Additionally, the (GTG) 5 primer can be applied to generate unique products from different Aspergillus species that can then be converted to sequences, and the characterized amplified regions can aid in taxonomic identification (Batista et al., 2008). Microsatellite analysis of Vietnamese A. flavus strains (isolated from corn and peanut) revealed high genetic diversity (Tran-Dinh et al., 2009). The microsatellite markers presented here will be useful for investigating the diversity and population structure of A. flavus and A. parasiticus (Tran-Dinh and Carter, 2000). The dendrogram produced using the ISSR markers showed no relationship between the clustering of the isolates and their geographic origin. The dendrogram produced using the ISSR data showed high genetic similarity according to the geographical origin (Batista et al., 2008). Genetic relationships were found between 84 strains of A. flavus isolated from Vietnam. No correlation was found between the geographic origin of the strains, and no genotype was evident. For example, the strains collected from both northern and southern regions were interspersed throughout the dendrogram (Tran-Dinh et al., 2009). ISSR markers can differentiate between aflatoxigenic and non-aflatoxigenic strains, and the ISSR primers showed a relationship between the ISSR dendrogram and the AF-producing ability of the isolates, especially when using primers $(\mathrm{GTG})_{5}$ and $(\mathrm{GACA})_{4}$. High genetic diversity was observed in the 84 strains, with no evident correlation detected between strain toxigenicity and genotype (Tran-Dinh et al., 2009). A. flavus strains were isolated from different oil seeds (groundnut, sunflower, and soybean), and four of these isolates were found to be nontoxic, while eight were toxic. No correlation was found between AF production and an ISSR dendrogram (Hatti et al., 2010).

\section{ACKNOWLEDGMENTS}

Research supported by the King Saud University, Deanship of Scientific Research, College of Science Research Center.

\section{REFERENCES}

Abd El-Aziz Abeer RM, Al-Othman Monira R, Al-Sohaibani SA, Mahmoud MA, et al. (2012). Prevention of aflatoxin contamination of maize by Aspergillus flavus through aqueous plant extracts in Saudi Arabia. Afr. J. Microbiol. Res. 6: 6931-6935.

Ahsan S, Bhatti IA, Asi MR, Bhatti HN, et al. (2009). Occurrence of aflatoxins in maize grains from central areas of Punjab Pakistan. Int. J. Agri. Biol. 12: 571-575.

Amer OE, Mahmoud MA, El-Samawaty AMA and Sayed RM (2011). Non liquid nitrogen-based-method for isolation of DNA from filamentous fungi. Afr. J. Biotechnol. 10: 1437-1441.

Batista PP, Santos JF, Oliveira NT, Pires AP, et al. (2008). Genetic characterization of Brazilian strains of Aspergillus flavus using DNA markers. Genet. Mol. Res. 7: 706-717.

Christian G (1990). HPLC Tips and Tricks. Great Britain at the Iden Press, Oxford.

Chulze SN (2010). Strategies to reduce mycotoxin levels in maize during storage: a review. Food Addit. Contam. Part A Chem. Anal. Control. Expo. Risk Assess. 27: 651-657.

Czerwiecki L, Czajkowska D and Witkowska-Gwiazdowska A (2002). On ochratoxin A and fungal flora in Polish cereals from conventional and ecological farms. Part 2: occurrence of ochratoxin A and fungi in cereals in 1998. Food Addit. Contam. 19: 1051-1057.

Davis ND, Iyer SK and Diener UL (1987). Improved method of screening for aflatoxin with a coconut agar medium. Appl. Environ. Microbiol. 53: 1593-1595.

Domsch KH, Gams W and Anderson TH (1993). Compendium Fungi. Academic Press, London.

Egel DS, Cotty PJ and Elias KS (1994). Relationships among isolates of Aspergillus sect. flavi that vary in aflatoxin 
production. Phytopathology 84: 906-912.

Fente CA, Ordaz JJ, Vazquez BI, Franco CM, et al. (2001). New additive for culture media for rapid identification of aflatoxin-producing Aspergillus strains. Appl. Environ. Microbiol. 67: 4858-4862.

Franco CM, Fente CA, Vazquez BI, Cepeda A, et al. (1998). Interaction between cyclodextrins and aflatoxins Q1, M1 and P1. Fluorescence and chromatographic studies. J. Chromatogr. A 815: 21-29.

Frisvad JC, Skouboe P and Samson RA (2005). Taxonomic comparison of three different groups of aflatoxin producers and a new efficient producer of aflatoxin B1, sterigmatocystin and 3-O-methylsterigmatocystin, Aspergillus rambellii sp. nov. Syst. Appl. Microbiol. 28: 442-453.

Gao J, Liu Z and Yu J (2007). Identification of Aspergillus section Flavi in maize in northeastern China. Mycopathologia 164: 91-95.

Gashgari RM, Shebany YM and Gherbawy YA (2010). Molecular characterization of mycobiota and aflatoxin contamination of retail wheat flours from Jeddah markets. Foodborne Pathog. Dis. 7: 1047-1054.

Gehlot P, Purohit DK and Singh SK (2011). Molecular diagnostics of human pathogenic Aspergillus species. Indian J. Biotechnol. 10: 207-211.

González HH, Resnik SL, Boca RT and Marasas WF (1995). Mycoflora of Argentinian corn harvested in the main production area in 1990. Mycopathologia 130: 29-36.

González PML, Alonso VA, Sager R and Morlaco MB (2008). Fungi and selected mycotoxins from pre-and post fermented maize silage. J. Appl. Microbiol. 104: 1034-1041.

Hadrich I, Makni F, Ayadi A and Ranque S (2010). Microsatellite typing to trace Aspergillus flavus infections in a hematology unit. J. Clin. Microbiol. 48: 2396-2401.

Hatti AD, Taware SD, Taware AS and Pangrikar PP (2010). Genetic diversity of toxigenic and non-toxigenic Aspergillus flavus strains using ISSR markers. Int. J. Curr. Res. 5: 61-66.

Irshad S and Nawab R (2012). Molecular characterization of seven different species of Aspergillus through random amplified polymorphic DNA (RAPD) and enzyme analysis. J. Microbiol. Res. 2: 47-50.

Lourenço A, Durigon EL, Zanotto P, Cruz Madeira JE, et al. (2007). Genetic diversity of environmental Aspergillus flavus strains in the state of São Paulo, Brazil by random amplified polymorphic DNA. Mem. Inst. Oswaldo Cruz 102: 687-692.

Mahmoud MA, Al-Sohaibani SA, Abdelbacki AM, Al-Othman MR, et al. (2012). Molecular characterization of the pathogenic plant fungus Rhizoctonia solani (Ceratobasidiaceae) isolated from Egypt based on protein and PCRRAPD profiles. Genet. Mol. Res. 11: 3585-3600.

Mahmoud MA, Al-Othman MR and Abd-El-Aziz ARM (2013). Mycotoxigenic fungi contaminating corn and sorghum grains in Saudi Arabia. Pak. J. Bot. 4: 1831-1839.

Martins HM, Almeida I, Marques M and Bernardo F (2008). Interaction of wild strains of Aspergilla with Aspergillus parasiticus ATCC15517 and aflatoxin production. Int. J. Mol. Sci. 9: 394-400.

Murphy PA, Hendrich S, Landgren C and Bryant CM (2006). Food Mycotoxins: An Update. J. Food Sci. 71: 51-65.

Paranagama PA, Abeysekera KH, Abeywickrama K and Nugaliyadde L (2003). Fungicidal and anti-aflatoxigenic effects of the essential oil of Cymbopogon citratus (DC.) Stapf. (lemongrass) against Aspergillus flavus Link. isolated from stored rice. Lett. Appl. Microbiol. 37: 86-90.

Pascale M (2009). Detection methods for mycotoxins in cereal grains and cereal products. Proc. Nat. Sci. Matica Srpska Novi. Sad. 117: 15-25.

Placinta CM, D'Mello JPF and Macdonald AMC (1999). A review of worldwide contamination of cereal grains and animal feed with Fusarium mycotoxins. Anim. Feed Sci. Technol. 78: 21-37.

Raper KB and Fennell DI (1965). The Genus of Aspergillus. Williams \& Wilkins Company. Baltimore.

Rocha LO, Nakai VK, Braghini R, Reis TA, et al. (2009). Mycoflora and co-occurrence of fumonisins and aflatoxins in freshly harvested corn in different regions of Brazil. Int. J. Mol. Sci. 10: 5090-5103.

Sepahvand A, Shams-Ghahfarokhi M, Allameh A, Jahanshiri Z, et al. (2011). A survey on distribution and toxigenicity of Aspergillus flavus from indoor and outdoor hospital environments. Folia Microbiol. 56: 527-534.

Tran-Dinh N, Pitt JI and Carter D (1999). Molecular genotype analysis of natural toxigenic and nontoxigenic isolates of Aspergillus flavus and Aspergillus parasiticus. Mycol. Res. 103: 1485-1490.

Tran-Dinh N and Carter D (2000). Characterization of microsatellite loci in the aflatoxigenic fungi Aspergillus flavus and Aspergillus parasiticus. Mol. Ecol. 9: 2170-2172.

Tran-Dinh N, Kennedy I, Bui T and Carter D (2009). Survey of Vietnamese peanuts, corn and soil for the presence of Aspergillus flavus and Aspergillus parasiticus. Mycopathologia 168: 257-268.

Wang X, Wadl PA, Wood-Jones A, Windham G, et al. (2012). Characterization of expressed sequence tag-derived simple sequence repeat markers for Aspergillus flavus: emphasis on variability of isolates from the southern United States. Mycopathologia 174: 371-382. 
Williams JG, Kubelik AR, Livak KJ, Rafalski JA, et al. (1990). DNA polymorphisms amplified by arbitrary primers are useful as genetic markers. Nucleic Acids Res. 18: 6531-3535.

Yassin MA, Moslem MA and El-Samawaty AMA (2012). Mycotoxins and non-fungicidal control of corn grain rotting fungi. J. Plant Sci. 7: 96-104.

Yin YN, Yan LY, Jiang JH and Ma ZH (2008). Biological control of aflatoxin contamination of crops. J. Zhejiang Univ. Sci. B 9: 787-792. 